ship that the statement that "no conditions will be placed on the money transferred to customer departments, but the expectation is that it will be spent to commission applied research work from the research councils" is perhaps not as weak as it sounds. Nevertheless, staff will need to have assurances that there are no intentions by departments suddenly to cut back on the amount of their commissioned research with the research councils; departments must plan their commissioned research with the research councils on the basis of five-year rolling programmes.

The most important paragraphs about the research councils are those concerning the new Council for Scientific Policy. The government has got the composition right. And it has strengthened its authority. That the CSP "will know and be able to take into account the size and nature of the work to be commissioned by the customer departments", and that the government will consider its recommendations in planning future totals of public expenditure on research and development, is not only a safeguard to the research councils and the universities, but potentially a means of bringing a wider viewpoint to bear on government decisions about civil research and development which could be of great benefit to all parties concerned.

There is a host of detailed matters to be cleared up in the wake of the white paper. Some of these will be of major significance in determining how things work out. The government has placed the greatest possible emphasis on partnership and cooperation with and between the various parties. Everything will depend on that spirit being an integral part of the package throughout.

\section{Requiem for the Nature Conservancy}

\section{This comment on last week's white paper is by a government scientist.}

Although all research supported by the government will, eventually, be affected if the recommendations of the white paper, Framework for Government Research and Development (Cmnd. 5046) are implemented, the only body which will be totally changed is the Nature Conservancy. The conservancy has, at present, two sides of almost equal size. The conservation branch is described in the white paper as being responsible for "the management of national nature reserves, and advisory, educational and protective work on wild life conservation". The other side, the research branch, is said to engage in "research, part ... directly applied to the solution of conservation problems". The proposal now is to abolish the Nature Conservancy in its present form, leaving only the research branch within the Natural Environment Research Council, mostly financed by that council, but with some 30 per cent of the research funds transferred to the Department of the Environment, which will place research contracts, possibly with NERC. The conservation branch is to be transferred bodiiy to the Department of the Environment, under a new and undefined Nature Conservancy Council established by the Secretary of State and subordiante to his department.

The white paper's descriptions of the branches of the conservancy are not strictly accurate. As was pointed out by $\mathrm{Dr}$ Kenneth Mellanby in his introduction to the recent Monks Wood Experimental Station report (Nature, 237, 246 ; 1972) the research staff is in fact deeply involved in both advisory and educational work, and any distinct divisions between research and conservation are meaningless. Almost all members of the research staff of the conservancy value this association with conservationists, both in their own organization and, increasingly, in voluntary bodies. This association results in a unique enthusiasm for conservation, and for the application of the results of conservation research, which would not otherwise exist. There is also a feedback from these contacts which encourages the research scientists to direct their efforts so as really to help with practical conservation.

The writers of the white paper were not the first to be worried because the Nature Conservancy does not fit neatly into the accepted pattern of a research council. The Slater Report in 1962 advocated a split along similar lines. When, however, the Trend Committee gave fuller considerations to its proposals in 1963, and when it implemented the suggestion that the Natural Resources Research Council (later renamed Natural Environment Research Council) should be set up, the first responsibility allotted to this new council was to include "ali the functions now exercised by the Nature Conser- vancy, including the management of nature reserves". All other recommendations for reorganization have also advocated keeping research and management together. Thus in 1969 the Select Committee on Science and Technology, considering the position of the conservancy in NERC, stated firmly: "All the evidence we have heard obliges us to conclude that conservation and research must go hand in hand, and that on balance it is desirable that they should be kept together under one body, even at the risk of compromising the Haldane principle". Again, in 1972, the Lucas Committee, enquiring into relationships between NERC and the conservancy, said that although at the outset some of its members had doubts about the wisdom of combining the two branches of the conservancy, all were won over by the evidence to support the existing situation, and they recommended as follows: "Effective conservation, in the present state of knowledge of the management of plant and animal communities, demands increased knowledge, so that conservation and research functions should be closely associated; these two Nature Conservancy functions should not be in different organizations".

Recently the conservancy has been involved in "A Nature Conservation Review" in which sites of ecological importance throughout Britain have been listed and evaluated. This is an essential blueprint for Britain's future conservation programme and for the safeguarding of potential nature reserves. The review was produced by the cooperative efforts of conservation and research branches; had they already been divorced, it could not have been written. How fortunate that it was completed in time!

It would be wrong to gloss over the differences that have occurred between the conservancy and NERC. Most of the staff, and most conservationists, regretted the loss of its independent research council status when it was absorbed in NERC, and attempts to regain this independence have been made. Recently, however, when this solution appeared to be impossible, closer integration within NERC of an undivided conservancy has been increasingly welcomed. It has been realized that the semi-independence of the conservancy has weakened NERC, and conservancy staff were, at last, coming to agree with the Lucas Committee that a strong NERC could foster all sides of conservation if all worked together to that end. The proposals in the white paper come at just the wrong time. They will do much to destroy the enthusiasm of those who have made the reputation of the Nature Conservancy so respected throughout the world. 